\title{
The Economics of Digital Business Models: A Framework for Analyzing the Economics of Platforms
}

\author{
ERIC BROUSSEAU * \\ EconomiX, Université de Paris X \& IUF \\ THIERRY PENARD \\ CREM, Université de Rennes \& Marsouin
}

\begin{abstract}
The paper proposes an analytical framework for comparing different business models for producing information goods and digital services. It is based on three dimensions that also refer to contrasted literature: the economics of matching, the economics of assembling and the economics of knowledge management. Our framework attempts to identify the principal trade-offs at the core of choices among alternative digital business models, and to compare them in terms of competitiveness and efficiency. It also highlights the role played by users in the production of information goods and competition with pure suppliers.
\end{abstract}

\section{Introduction}

The booming growth in computers and electronic networks has greatly transformed the production and consumption of information. With the arrival of the last generation of Information Technology (IT), symbolized by the Internet, information goods and services are characterized by significant network externalities, high fixed costs and variable costs (of reproduction) tending toward zero. Those features are due both to the particularities of the technologies that have been developed to manage information - characterized by high levels of interoperability and increasing returns of adoption; cf. Shapiro and Varian (1999) - and to the specificities of information as a public good (Arrow, 1962). The notion of

\footnotetext{
* Contact Author. EconomiX, Université de Paris X, Bâtiment K; 200 avenue de la République; F-92001 Nanterre Cedex; France. Email: eric@brousseau.info While working on this paper, the author was a visiting fellow at the International Center for Economic Research (ICER), Turin, Italy. ICER is warmly thanked for its support. The authors would like to thank the Centre National de la Recherche Scientifique (CNRS) for backing their research with the "Information Society" Program. We also received financial support from France Télécom Research and Development, the CDC Foundation for Research, the European Union (DG Research as part of the "Ref-Gov" Integrated project) and Marsouin (Brittany region). We would like to warmly thank all these sponsors. We also got very useful comments from participants to conferences and workshops organized by the GDR TICS (CNRS), ISNIE, ITS. We are grateful to them and to the organizers. Usual caveats apply.
} 
digital economy is often used to qualify the new economics of information industries. Among the innovations carried out by the digital economy, new business models are central.

In this paper, we define a business model as a pattern of organizing exchanges and allocating various costs and revenue streams so that the production and exchange of goods or services becomes viable, in the sense of being self-sustainable on the basis of the income it generates. With the passing of time, it is easier to identify the commonalities among the new business models that exploded with the growth of the Internet, although some had existed before. We believe they combine new and innovative ways of organizing the relationship between demand and supply, with pricing strategies that take into account network externalities, the specificity of information and the ability to differentiate and discriminate, thanks to digital technologies.

These new business models contradict the prediction of a massive disintermediation caused by the strong development of digital technologies and of the Internet., Even if the Internet can reduce coordination costs, intermediaries are still needed. First, matching demand and supply plans, then performing transactions remains costly. Second, combining several digital goods to benefit from their interoperation - as is the case when a content is processed by a software run on a technical interface -is certainly much easier than it was in the past, thanks to standardized interfaces. However, it remains resource and time consuming to guarantee effective inter-operability between digital goods to benefit from a value-added service. Third, while a profusion of information goods is available both onand off-line, it remains challenging to guarantee a user access to the information or piece of knowledge they need. Those who can provide knowledge should receive appropriate incentives. Potential users should be guaranteed access. These together led platforms to emerge to facilitate coordination in the production and marketing of information goods. Many of the Internet success stories - E-Bay, Amazon, Google, Yahoo, Autobytel - have developed business models based on the concept of platforms assembling components, then bundling them into packages that correspond to consumers' complex and specific needs.

These innovative forms of intermediation should have strong long-run impacts on the market structures, organization and performance of the economy. Therefore, it is vital to understand how the providers of these services can cover their costs (direct sales, subscription fee, advertisements, etc.), what are their incentives to provide alternative intermediation services (that is, are these alternative models characterized by contrasted levels of pay-off?), how these models compete with each other, what is the value added by these intermediaries, etc.?

This paper aims, therefore, to provide insights into the economics of the new business models in general, and of the business models of digital platforms in particular. The category of platforms we are interested in is larger than the category on which the literature on "digital intermediation" focuses. Our platforms serve to organize exchange and production, to assemble components and manage information and knowledge. They range from software companies like Microsoft, which buy various software components and combine them with its built-in components to provide users with a ready-to-use package, to these portals that provide information services to their customers by arranging access to various information services provided by a third party. Our understanding of platforms is thus broader than what is generally qualified as infomediaries (like to Referrals, Shopbots, and Gatekeepers), in the literature on digital industries. 
We also do not focus on Internet-based business models only. We are interested, in digital industries in general, and we believe the proposed framework applies to the whole industry. Moreover, since many activities are intermodal - that is, they have digital dimensions but also significant links with physical products, infrastructures and related services - digital business models (assuming we can isolate them) are likely to intersect with many conventional models. More generally, the new concepts and strategies invented online or in the digital world can even influence business models in general, because they change the minds of decision makers, who therefore can innovate by implementing, for instance, new marketing strategies in industries not directly associated with digital ones (see also Hawkins (2002) on this).

Our paper therefore proposes a framework highlighting the more relevant dimensions that enable us to differentiate the various digital business models. We highlight these aspects, and for each of them, point out the essential tradeoffs agents face when creating a business model. We seek to be exhaustive in being able to deal with most of the possible business models, while remaining parsimonies in describing them, thanks to the fewest possible number of dimensions. We first describe our vision of digital activities. It highlights three tasks potentially performed by platforms: matching demand and supply, assembling composite goods to meet users' needs, managing information knowledge to allow quality enhancement and innovation (section 2). We then show how various intermediaries perform these tasks, and this allows us to compare them using the three dimensions mentioned earlier. Indeed, any business models correspond to alternative choices made to carry out these three tasks. In the following sections, we explore, therefore, the most relevant choices that should be made in terms of matching (section 3), of assembling (section 4) and of knowledge management (section 5). To do so, we refer to existing literature on (electronic/on-line) business models. Indeed, our three dimensions correspond to different literature, which is briefly synthesized. In each section, we present the main lessons to be drawn from each of these literatures, which lead us to identify two main tradeoffs in each case. Section 6 discusses this framework and concludes.

\section{A framework for analyzing digital business models}

This section proposes a vision of the production and distribution process of digital goods, aimed at grasping the essential dimensions of digital business models to differentiate them, according to the smallest possible number of relevant characteristics.

\subsection{Digital activities as modular activities}

What are the characteristics of demand and supply in the case of digitally intensive goods and services? Three observations can be made.

Observation 1: Digital goods and services are of a modular nature. Basic components corresponding to "functionalities" - are assembled to produce valuable services that meet consumers' needs. Consumable services are therefore made up of "packages" of basic functions.

This fits with the Lancaster (1979) vision of consumption and goods. Consumers are seeking a collection of basic attributes or components. A specific combination of digital 
contents and information processes results in "composite goods". The way packages are assembled is a major differentiating factor across digital business models. Moreover, competition between "provision schemes" plays at two levels. First, a single need can be met by competing "packages". Second, a given package can be assembled through different (organizational) processes. That leads to a competition among organizational models.

Observation 2: Digital activities are characterized by three basic operations:

- The production of functionalities/modules. Functionalities are linked to the provision of either tangible goods or information services, or a mix of both.

- The assembling of functionalities. Each module has no value by itself. They are multipurpose, and have to be combined with each other to produce a valuable service that fits with particular needs for a specific category of users.

- The consumption of services generates value (either because the user is satisfied - in the case of final users - or because he can use the service to generate new services or knowledge - in the case of producers).

This second observation mostly draws from the first one. Digital goods are composite goods made of components that are multipurpose in the sense that they can be implemented in different goods. But these components are of no value unless combined to produce the needed services. Software is a good example. A spreadsheet or a word processor, or even a more specialized software aimed at managing financial operations for small businesses, are made up of basic components that manage the screen, the hard drive, printing resources, and that operate basic - for example, sorting, calculating - or more sophisticated operations - for example, checking grammar or turning tables into illustrations. Any software is made up of basic components that are useless when considered alone and recombined differently in various softwares. The same applies for many information services or databases. They are produced by combining data or information flows (usually coming from heterogeneous sources in contrasted formats), with processes for organizing, stocking, retrieving and distributing them. ${ }^{1}$

Observation 3: Users (or consumers) are not neutral in the process of value creation, since they can themselves assemble the functionalities, and since they can generate valuable information or knowledge.

This third observation is based on two ideas. First, digital technologies are a set of integrated techniques that rely on a common basic principle: the transformation of any

\footnotetext{
${ }^{1}$ Our vision of the digital industries is therefore a fractal one, in that the structure of the production process is the same at various "levels". Lines of machine codes are assembled to create a source code. Source code is assembled to create "objects", which are themselves assembled to create software. All types of software have to be assembled to create an "application”, like a computerized inventory management system. These applications are assembled with others to create information services, which are themselves assembled with other (sometimes tangible) services to create a service provided to a user, etc. Our model can therefore apply to a wide set of tiers of the information economy, from the organization of production and exchange among software developers to the relationship established between large media, digital and network service companies.
} 
signal - whatever its form (voice, image, text), or nature (content or algorithm) - into a set of digits that can be processed and transmitted by the same technical system according to similar procedures. This generates a de facto meta-standard of interface that allows for the integration and interoperability of digital sequences and digital information processing devices. Those agents who want to integrate heterogeneous digital components have "simply" to manage interfaces; that is, to implement gateways and translators among them. When "universal” interface standards and protocols exist, as is the case with the Internet, the integration/assembling of components requires little effort. Interoperability among components is more complex and costly in the case of other technologies because it does not depend on the management of interfaces only. Often, components have to be designed in relation to the other components. There is a mutual specialization among components (relating to the idea of asset specificity as described by Williamson, 1985), while in the digital world, most components are compatible with one another's (if interfaces are appropriately managed). This allows consumers to credibly become their own assembler. There are many examples of this in the digital industries. Most PC users, for instance, assemble themselves a set of hardware and software resources to customize their information system. The users of open-source software are also often their own assemblers. Users being able to become assemblers, a potential competition between them and specialized assemblers exists.

Second, in a market for information or for knowledge, the supply and the demand sides are difficult to disentangle since any agent is both information (or knowledge) user and provider. There are many different situations, ranging from the spontaneous feedback of the consumer, to the innovation he can derive from what he learnt, and including his insights into the way the services could be better adapted to his needs or enhanced (Henkel and von Hippel, 2005). Actively or unintentionally, the user of a service generates information, and sometimes knowledge, which can be of value, either for the other users (who could benefit from information on the quality of the service, or on its optimal conditions of use) or for the agents involved in its production (who could better target or design their output). To some extent, the "user" can be seen as a producer of intermediate goods derived from the information he has consumed. This is typically the case for developers in open source software communities, who "invent around" pre-existing lines of codes, for many digital artists that rearrange digital contents to produce new works of authorships, or for those consultants who reorganize and synthesize existing information. There is, therefore, potential co-operation between the producers of functionalities and users, since the latter produces information that can be combined with functionalities, and in some cases that can compete with them. More generally, "coopetition” occurs in digital industries. Users can provide the suppliers of functionalities with useful knowledge and information to enhance them, or they can themselves become producers of functionalities. They can also provide the assemblers with information enabling the latter to more efficiently target the users, and can also decide to substitute them by assembling final services for themselves.

Figure 1 sums up our observations and presents our analytical framework. Digital markets can be described through the relationships between three categories of agents: the producers (of functionalities), assemblers and consumers. The latter consume services, which are packages of functionalities assembled either by themselves or by intermediaries: the assemblers. The consumption of the service generates information that can become an input, either for producing functions or for assembling them. 
Our analysis of digital business models consists of identifying the way transactions can be organized between these three categories of agents. We focus, in particular, on the costs and benefits, borne or received, by the various players when a platform provides, or not, coordination services between the two sides of the "market". We also consider various options for the platforms to deliver this coordination service. In particular, we analyze the consequences of alternative differentiation/competition strategies, as well as alternative options for generating flow of information goods and revenues. Competition between and within the three categories of players determines the sustainable models and the distribution of wealth among them.

Production Assembling

Consumption

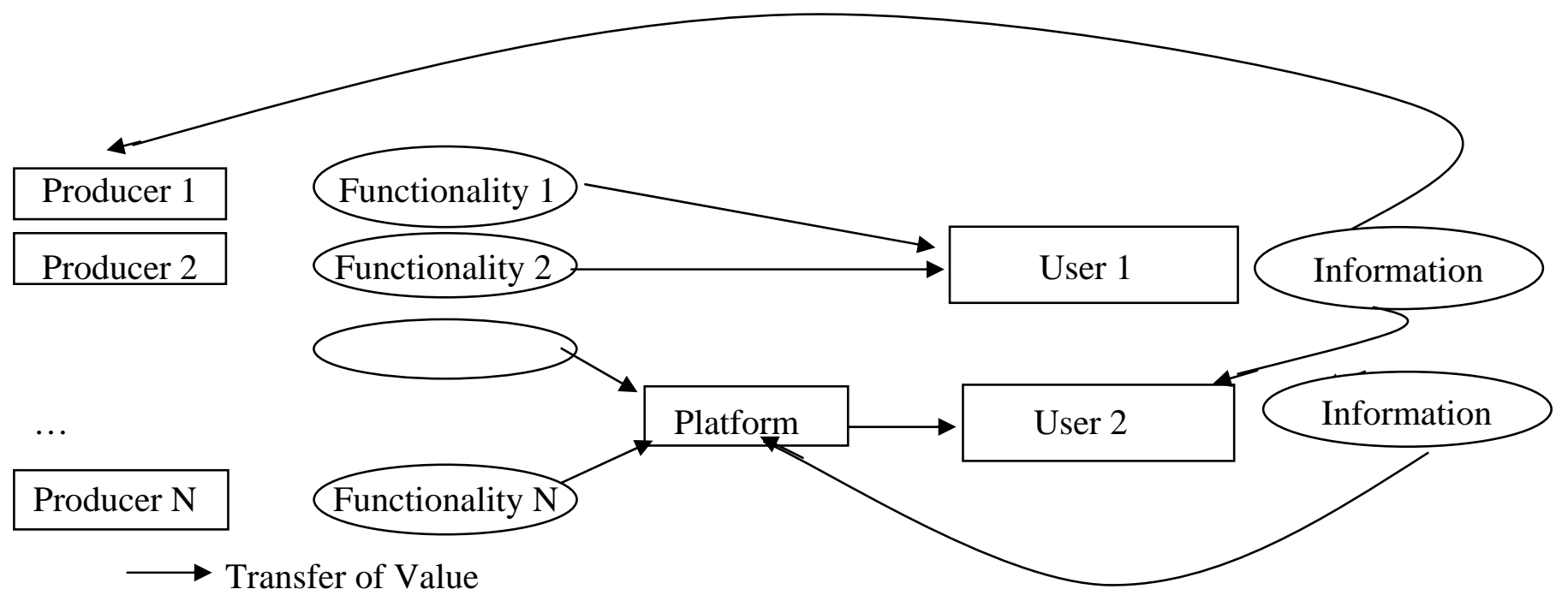

Figure 1: The analytical framework

\subsection{Three dimensions for comparing business models}

We suggest three “dimensions” for comparing most digital business models, which are adequate for grasping their main characteristics. They correspond to three contrasting domains of existing literature on DBM.

The first one refers to the economics of intermediation and focuses on transaction costs. In this perspective, digital networks are mainly understood to mean market places where supply needs to meet demand. The performance of transactions between "providers" and "consumers" (of functions) requires dedicated resources for solving a set of transactional difficulties (matching demand and supply, secure transactions, risk management, etc.). From this viewpoint, DBMs rely on the capacity to organize transactions between the two sides of the "market", so as to save costs or make transactions more efficient.

The second dimension refers to the economics of assembling per se, and focuses on what we call "assembling costs". From this viewpoint, digital networks are generally considered production networks within which productive resources (the "functionalities") are combined (assembled) to produce an output, which can be of use for users. Alternative ways of combining resources results in trade-offs between the levels of assembling costs, the ability to meet users' needs and extract value from consumers to remunerate the efforts 
made by the producers of functionalities. DBMs refer to alternative ways of solving this trade-off.

The third dimension refers to the economics of knowledge management, and focuses on the efficiency with which the information generated by digital goods' users is used to improve services and innovate. From this viewpoint, digital networks are generally understood to mean tools enabling the sharing of information and knowledge. Alternative ways of doing so impact on the efficiency of collective accumulation and creation of knowledge, especially by influencing individual incentives to share information with others, the ability to retrieve relevant information for each individual innovator, and the distribution of knowledge (which is a public good). Alternative DBMs have different capabilities for efficiently using existing cognitive resources and organizing the accumulation of knowledge.

In the following sections, we explore existing literature to highlight the main trade-offs at the origin of different business models. This is vital for grasping the economic properties of alternative digital business models. Before doing so, it is important to highlight three key points.

First, we speak about dimensions because we view the creation of a business model by an entrepreneur or community as a positioning within this three dimensional space (illustrated in Figure 2). Indeed, they must choose a way to organize transactions, a way to assemble functionalities, and a way to manage knowledge when they want to produce and distribute digital goods. In the following, we will examine separately each dimension of this complex choice, but any DBM corresponds to a set of choices in each of these dimensions. For simplicity, we will refer to examples with reference to one of their dimensions only, but this does not mean choices are made solely on this dimension. Implicitly or not, choices are made by DBM designers across the three dimensions. For instance, if an agent decides to organize a marketplace, he apparently chooses to organize only the "transactional dimension", so as to make money by providing solutions that reduce transaction costs and/or enhance the efficiency of matching. However, he also has to choose whether he will allow suppliers to compete between themselves (or cooperate to provide complementary goods), and whether he will play a role in allowing players to complete the cognitive loop.

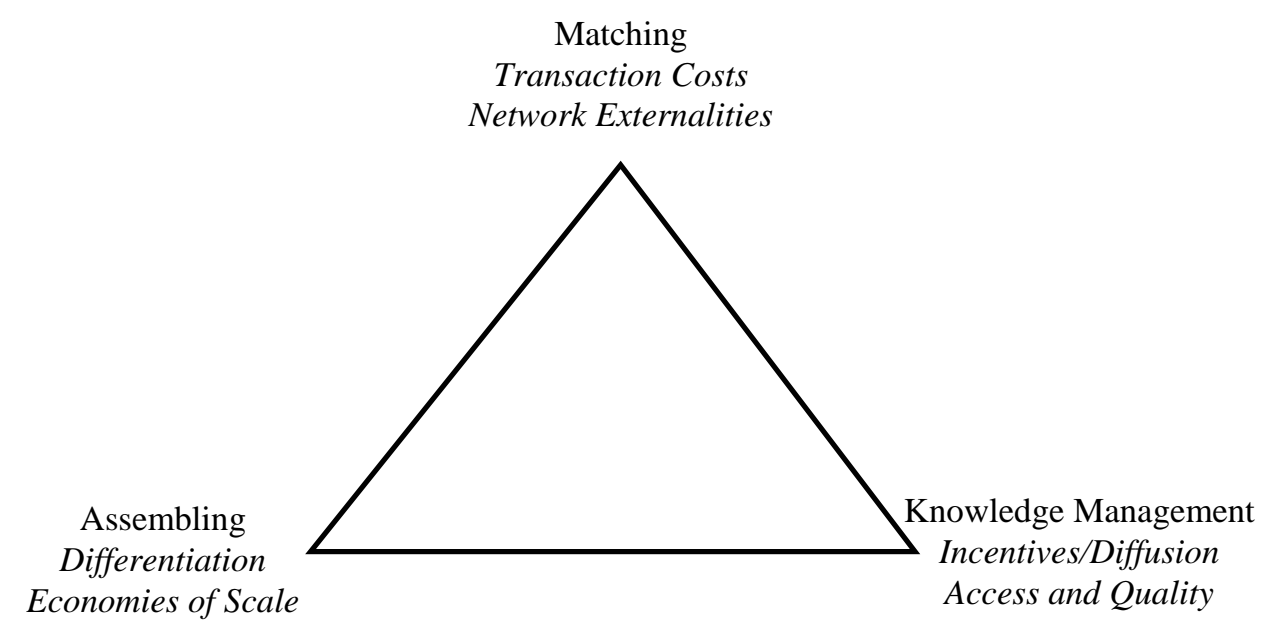

Figure 2: Three dimensions for comparing digital business models 
Figure 2 reads as follows: at each angle, we find the pure business models: either pure matching (for example, dating services) or pure knowledge management (for example, online epistemic communities) or pure assembling (for example, a telecommunications access provider). The surface corresponds to various combinations of the three services. For instance, online travel agencies generally provide a balanced mix of the three services since they allow identifying providers (matching), they manage knowledge about them (for example, assessment by clients, ranking by guides, etc.), and can also manage the provision of several combined services (transportation, car renting, hotel reservation, access to various entertainment services). They are located in the middle of the surface. EBay, for instance, is clearly a mix of matching and knowledge management services. It is on the right hand edge of the triangle, somewhere in-between the base and the summit.

Second, we consider these dimensions as independent. Choices made in terms of transaction organization are independent of those made for knowledge management. This is even true when referring to "intermediation". The matching of demand and supply can be centralized by an intermediary, but knowledge management decentralized; and vice versa. By choosing to centralize or decentralize each of the three operations, agents establish models combining various trade-offs, and the economics of alternative DBMs must take these into consideration.

Third, each of the possible business models in our triangle can be dominated by a monopolist benefiting from the winner-takes-all dynamic characteristic of digital industries (Shapiro and Varian, 1999; Varian, 2000; and Hand, 2001). Competition is therefore between business models rather than within each of these business models. This is well illustrated in the competition between Linux and Microsoft (see, for instance, McKelvey, 2001), between Amazon and the shopbots, between Google and Yahoo!

Our analysis differs from managerial or economics literature that analyzes "business models" at firm level only, by considering, in fact, how investment in online service provision should be performed (both in term of volume/temporality and in terms of technical choices), and the type of marketing strategies to be implemented (pricing, customer loyalty management, provision portfolio) so as to guarantee successful returns on investments (as it is done, for instance, by Melo de Brito Carvalho and Siegel (2002) for online banking services). Also, our analysis differs from the "strategic" one proposed by Varian and Shapiro (1999), who focus on the possibilities of pricing information and managing lock-in effects. Our own approach focuses on alternative options for coordinating the various parties involved in the production and use of information and network-based services. It insists on the horizontal and vertical "co-opetition" phenomena along transaction chains, and analyzes how value can be created and shared to result in sustainable models.

\section{The economics of matching and intermediation}

In this section, we take a brief look at literature on matching and intermediation, before pointing out the main trade-offs.

\subsection{Infomediaries and two-sided platforms}

The first dimension of the relationship between producers of functionalities and users involves reducing it to a simple exchange. The issue then is to match "bids" and "calls", 
and to ensure the actual performance of transactions. Indeed, performing exchanges between a set of suppliers and a set of demanders requires (see Spulber, 1996; and Brousseau; 2002): (i) matching agent's plans; (ii) reconciling these plans in time and space when they do not spontaneously match (logistic matching); (iii) securing transactions because information asymmetries and bounded rationality generate adverse selection, moral hazards and non-enforcement problems; (iv) market clearing since liquidity constraints and risk can prevent agents from realizing their optimal production or consumption plans (resulting in shortage of supply or demand).

The governance of transaction has been deeply analyzed for the past 25 years with the development of transaction cost economics (Williamson, 1975, 1985) and incentive analysis (with seminal contributions by Arrow, 1971; Akerlof, 1970; and Stiglitz 1977) ${ }^{2}$. Economists have recently taken a broader approach by considering the "structures" organizing relationships between participants in a market in two ways: the economics of institutions (from North, 1990, to recent contributions by Dixit, 2004), on the one hand, and the economics of market microstructures (initiated in financial economics and applied to the economics of commerce in particular by Spulber, 1996, 2003), on the other. The economics of institutions focuses on rules and enforcement mechanisms framing economic activities by "setting the rules of the game" (North), while, as pointed out by Spulber (1999) the economics of market microstructure analyzes the role and strategies played by agents seeking to coordinate or help others coordinate. The latter approach is therefore more appropriate for analyzing new business models for intermediation, since it focuses on strategies that can be taken by market players in a given institutional context.

The economics of market microstructure addresses the nature and impact of eintermediaries in two main categories of literature: the economics of intermediation and two-sided markets.

The economics of intermediation focuses on the impact of intermediaries on the level of transaction costs. At first sight, IT can cut information and transaction costs. Consequently, these technologies, and especially the Internet, enable the emergence of infomediaries, who are implementing new ways of exchanging information and contracting. The literature exploded in the late $1990 \mathrm{~s}^{3}$. As pointed out by Lucking-Reiley and Spulber (2001) it addresses three main issues:

- $\quad$ the performance of markets (search costs, ability to generalize auctions, etc);

- the evolution of market and industry structures (possible divestiture of large intermediaries, possible “disintermediation”, emergence of new players, etc.);

- and the sustainability of business models (performance of alternative intermediaries, dynamics of competition on the intermediation service market, etc.).

The second category of literature, the economics of two-sided markets, is based on the idea that, at a given level of transaction costs, their distribution among economics agents and the organization of interaction among them, can impact on the efficiency of coordination (the latter being qualified by the quality of matching and the volume of

\footnotetext{
${ }^{2}$ See Brousseau and Glachant (2002) for an overview of these approaches.

${ }^{3}$ See, for example, Bakos (2001), Baye and Morgan (2001, 2002), Caillaud and Jullien (2001, 2003), Arnold and Pénard (2007).
} 
transactions). A two-sided platform is an intermediary that faces two interdependent demands due to indirect network externalities (for example, between credit card holders and affiliated retailers). The intermediary can then implement discriminating pricing strategies to maximize their surplus by playing on cross-subsidization (for example, Parker and Van Alstyne, 2000; Rochet and Tirole, 2002, 2003, 2007; and Wright, 2004). This framework has been widely used to study info-mediation (see Hagiu, 2007). Playing on the capability to handle information at a low cost, quickly and flexibly, infomediaries can develop sophisticated matching services to increase the capability of a "bid" to meet an appropriate "call” and vice-versa

\subsection{Economics of intermediation: The central trade-offs}

The economics of intermediation and its application to online intermediation focuses on the management of externalities. The presence of a platform, of an intermediary, between supply and demand makes managing externalities more efficient, simply because the intermediary will internalise them, which provides him with the means to deal with them. Obviously, efficiency is a matter of adequate incentives, which is the case when the intermediary is the residual claimant of his intermediation efforts.

There are, however, many different categories of externalities dealt with by two-sided market literature, on the one hand, by literature on commercial intermediation, on the other. Two-sided market literature highlights externalities between the two sides of the markets, due to a combination of network effects and differential of price elasticities for the intermediation service. Externalities are linked to heterogeneity between agents. Commercial intermediation literature insists on externalities between the provision of various intermediation services. For instance, the provision of more information on the quality of transacted goods economizes on the provision of complementary services, such as the logistics for replacing/repairing damaged goods or insurance for compensating the customer for a loss of value.

Information technology reduces the constraints in designing solutions to support interindividual coordination in the economy, and facilitates the creation of viable alternative business models that choose to manage externalities between agents and coordination tasks on different bases.

Literature on two-sided markets emphasizes the importance of the structure of the intermediation market on the quality of intermediation. Indeed, in the most basic models, the quality of the matching services provided by the two-sided platform is linked to its ability to perform cross-subsidies between the two sides of the market. Subsidization of participants less likely to pay for intermediation services increases their participation in the matchmaking service and enhances its attractiveness for other participants, which increases the likelihood of all potential participants using the platform. In more sophisticated models, the platforms provide additional services for increasing the volume of transactions and quality of matching (that is, the probability of a "bidder" meeting the adequate "caller" and vice-versa). The platform can indeed "organize" the market in particular by controlling entry to avoid the provision of low quality, and therefore either guarantee a minimum level of quality or raise the average level of quality; which enhances the attractiveness of the platform. The other potential function of a matching platform is to regulate competition to guarantee efficiency of trade to the market participants. So it consists of monitoring how the deals between the two sides of the markets are settled to punish all kinds of anticompetitive behaviour. The capability to price discriminate, to control entry, and monitor 
behaviour strongly decreases if there are several competing platforms. Any competitive platform has an incentive to attract potential users by reducing the level of "taxation" or "regulation", which weakens the capability of platforms to provide optimal levels of service.

There is, therefore, an essential trade-off in terms of market structure for intermediation. Monopoly favours the capability to efficiently "organize" the exchange. In addition, since the service is provided for all traders, one may expect economies of scale and maximization of network effects. It obviously has a cost. The monopolist intermediary can capture rents. He may do so both because he is the single provider, but also because he possesses information on the value of the matching service for market players. On the other hand, competition in the provision of two-sided intermediation decreases the capability to provide efficient matching services, unless strong differentiation strategies are practiced by platforms, which brings us back to the monopolistic case.

Literature on commercial intermediation emphasizes complementarity and substitutability effects between the four services provided by commercial intermediation. As pointed out by Brousseau (2002), intermediaries can perform various tasks. By managing information about customers' demands and suppliers' offers, they facilitate the matching of plans. By performing logistic operations (such as holding inventories or moving goods), they adapt these plans when they do not spontaneously match. By dealing with information asymmetries between the two sides of the markets, they help solve problems arising from adverse selection, moral risk and defaults of enforcement. By ensuring the liquidity of exchanges when necessary, they allow market clearing. There are, however, many different ways of performing these tasks, leading to a wide range of possible business models. Spulber (1996) points out that bundling the provision of these services allows for their optimal combination given their relative costs, which varies according to the nature - in particular, their production constraints - of the transacted goods and characteristics of consumers (in particular, the diversity of their preferences and geographic distribution). A commercial intermediary - who holds property rights on transacted goods and is, therefore, the residual claimant of any effort to guarantee the optimal performance of selling them - has the right incentives to provide the optimal level of service. On the other hand, specialized intermediation service providers who act only as middlemen do not have the incentives and the capability to decide whether the service they provide is efficiently ordered by the transacting parties (since it depends on the provision of alternative intermediation services by other specialized providers). In addition, these intermediaries that provide unbundled services without being residual claimants do not have appropriate incentives if they are not facing strong effective competition. True competition means that the platform' users - the transacting parties - should be able to switch at no cost to alternative intermediation services providers.

Thus, the economics of commercial intermediation highlight a trade-off between a model of integrated commercial intermediaries that provides transacting parties with a service that will minimize transaction costs and guarantee market clearing, and a model of specialized intermediation service providers (logistic, matching, etc.) that may exhibit higher economies of scale and specialization. In the latter case, however, incentives to provide an efficient service strongly depend on the competitive pressure and transparency, 
on the market for services by intermediaries ${ }^{4}$. In the case of integrated commercial intermediaries, competition matters as well. However, it does not impact on incentives to provide an efficient service. It has a pure redistribution effect between the intermediary and users of the service.

All these elements highlight the fact that there is no one best business model, both in terms of platform and collective (and users') welfare. There are trade-offs among the models. What is clear is that there are, in any case, strong incentives for any intermediary either to be in a strong monopoly position to become a single-counter at the centre of the industry/market, or to strongly differentiate to be dominant in a niche. It obviously has a positive impact on its profitability. This results from a sometimes convergent, sometimes divergent, crossing-over of effects between a higher capability to capture rents on users and a higher or lower capability to manage cross subsidies between users and intermediation services. Since in a world where digital networks exist, users always have the possibility of bypassing intermediaries and relying on totally un-intermediated exchange to coordinate, it is worth noting that there is always a limit to the capability of monopolies to capture and be inefficient. Potential competition in matter of matching/intermediation exists even in cases where there are no direct competitors to the existing platforms. The degree of competition/contestability increases when there are alternative models of platforms. A good competitor to monopolist commercial intermediaries could be a set of (monopolist) specialized intermediation service providers (e. g. a combination of DHL, eBay and Visa vs. an on-line supermarket or general store).

\section{The economics of assembling: Qualitative matching in a context of mass-customization}

\subsection{Assemblers as demand and supply third parties}

Beyond the intermediation/matching service between the provider of a given functionality and its user, a platform can, in addition, provide an assembling service. This constitutes our second axis for distinguishing business models. The assembler brings sets of functionalities/modules together to fit the user's needs. It operates matching on quality by acquiring functionalities, bundling them, delivering a package and extracting value from users. Moreover, he has to technically "assemble" the components of the composite goods delivered.

In practice, an assembler can rely on contrasted economic tools to buy and integrate the various components of its service. He can, as Microsoft does, acquire the (start-up) firms that develop and market the functionality. He can, as many portals do, simply buy an operating license from an information provider. The notion of assembler is therefore quite wide - it ranges from the infomediaries that market information packages, such as TV channels or Internet portals, to industrial aggregators such as computer manufacturers.

Assembling generates costs made up of transaction and technical costs. Transaction costs are generated because the assembler has to do deals with the producers of the functionalities he buys and with the end customers. Technical costs result from the

\footnotetext{
${ }^{4}$ It must be pointed out that in case of unbundling (specialized intermediaries), there is a conflict between the positive effect of competition between specialized intermediaries, and the negative effect of competition on the capability of infomediaries to provide efficiently matching services.
} 
technical operations needed to actually make the various components bought on the market for functionalities both compatible and interoperable. Indeed, these components do not spontaneously interact together. Interfaces and gateways must be designed to turn the "package" into turnkey information goods.

Beyond digital industries, "assemblers" are becoming prominent in developed economies. They are pivotal for the "mass-customization" industrial model. This latter model is the way the industry responded to the need for more diversified and customized goods and services, linked to the increase in living standards. Standardized components or functionalities - are produced by mass production techniques and assembled on a flexible basis to meet the diversity and evolution of consumers' preferences, while also benefiting from economies of scale in production. Mass customization is intrinsically linked to the development, distribution and implementation of IT since they are required to manage the important information flows needed to coordinate customers and providers, the management of the supply chain, and of flexible production systems (for example, Hirst, 1997; Lee et al, 2000; Piller, 2002; Fulkerson and Shank, 2000, and Vrechopoulos, 2004). IT is the facilitator of flexible assembling for at least two reasons. First, flexible assembling is, by definition, an information intensive process. Digital technologies simply make possible the just-in-time management of the interdependent components of these highly complex production-logistic-distribution processes. Second, the increasing standardization of the technology in itself - symbolized by the Internet - allowed for the integration of various components of information systems, both within and among firms, which is a prerequisite for a seamless model of flexible assembling, combined with the capability of sellers to learn about their customers, finely adapt supply to their needs, and/or discriminate them based on pricing, so as to extract as much value as possible from associated marketing techniques.

It must be pointed out, however, that the need to rely on IT to finely adapt assembled packages to consumers' needs greatly depends on assembly and production costs. Bakos and Brynjolfson (2000) analyze the impact of digital technologies on assembling digital goods. Since the marginal costs of producing information goods and of aggregating them in packages dropped, any platform has a strong interest in developing a large-scale aggregation strategy. Bundling the provision of all kinds of information goods, even in the absence of network externalities or economies of scale or scope provides a huge competitive advantage since the provider is able to price discriminate, deter entry, eliminate small competitors and attract providers of any additional information goods, thanks to his resulting dominant position. Thus, when considering these specific market segments in which aggregation costs tend to zero, there is no great difference between an assembler and a matchmaker/intermediary. The need to assemble customized packages no longer holds and analytical results drawn from literature on matching apply to assembling. In the following, we consider the trade-offs of assemblers when costs of assembling matter.

The economics of assembling is still in its infancy, but several researchers have started analyzing competition and strategic interaction among providers of complementary functionalities/modules that must also choose to deliver them to users in a package assembled by a third part or directly (self-assembling). The assembler, on his side, has to choose whether or not he will adopt a sophisticated strategy to extract value from customers. Three strands of arguments have been developed so far. First, assembling costs, being to a large extent fixed and reproduction costs being nearly equal to zero, assemblers 
generate efficiency gains (economies of scale and scope). Moreover, by bundling services, assemblers increase the ability to capture consumer surplus, which is of value for the providers of functionalities. However, they have to be remunerated for the service they provide, and may eventually capture rents. This generates a trade-off both for the users and the producer of functionalities, who will balance efficiency gains with the costs of the intermediation service, and with the redistribution effect due to the presence of a third party that can adopt a strategic behaviour. ${ }^{5}$ Second, an assembler may choose to specialize in the assembling of some specific functionalities, which brings differentiation strategies into account. A trade-off between platforms assembling a wide set of modules (but resulting in some "pollution" effects; see below) and those focussing on a more specialized set (but targeting a smaller audience) may be highlighted. Third, the assemblers by developing ad-hoc gateways or specific standards of interfaces facilitate the coordination of innovation strategies and incite providers of functionalities to innovate. The relevant literature is reviewed in Bourreau, Dogan and Manant (2007).

The underlying literature is in Industrial Organization. In particular, the economics of network $^{6}$, the analysis of positive and negative effects of strategic coordination (in cartels and alliances) ${ }^{7}$ and the analysis of strategic network formation ${ }^{8}$ provide insights on the strategy followed by agents - here, our providers of functionalities - to decide to join a coalition or not - here, our platforms. The basic idea is that those providers of functionalities that do not join the platforms benefit from its impact and are better able to extract value from customers than those who do join. This is due to the cost of the platforms, which is borne only by those who join, while the benefits - the decreasing assembling costs - benefit all players since they increase the wealth of end users and therefore their propensity to pay for the functionalities, whether included in the package assembled by the platform or not.

The literature is still in its infancy. Indeed, assumptions are often made about shrinking assembly costs and the easiness of versioning and price discriminating of composite digital goods, led many scholars to underestimate the role of assemblers and to focus on simple intermediation. In its current state of development, however, this literature fails to analyze whether the nature of assemblers impact on their strategic capability. Neither does it explore the nature of competition between packages that would be differentiated but partly made up of the same components (which is often observed in the digital world).

Other, more applied literature could be taken into consideration to help solve these analytical shortcomings. Its theoretical background lies in strategic analysis and more precisely, in the resource-based approach to the question (for example, Pisano 1990; Teece et al, 1994; and Kogut and Zander, 1996). It focuses on understanding the strategies of digital assemblers by identifying the key capabilities enabling a digital goods provider to become the platform around which all the functionalities are assembled. We believe this

\footnotetext{
${ }^{5}$ Few theoretical models on the economics of assembling exist. An interesting approach to assembling is proposed by Economides and Katsamakas (2004). They focus on a technology platform (an assembler) and analyze pricing and cross-subsidization strategies. Brousseau and Pénard (2006) propose another theoretical framework for assembling, to examine the conditions in which an assembler can emerge on a digital market, and understand which components of the digital system the assembler is more likely to control and resell.

${ }^{6}$ See Economides (1996), and Economides and Salop (1992).

${ }^{7}$ For instance, Donsimoni, Economides, Polemarchakis (1986), Donsimoni (1985).

${ }^{8}$ Among others, Myerson (1977), Aumann and Myerson (1988), Jackson and Wolinsky (1996), Dutta and Jackson, (2000), Jackson and Watts (2002), Bala and Goyal (2000), and Goyal and Joshi (2003).
} 
questioning helps identify the most relevant trade-offs when it comes to comparing alternative business models for assembling.

\subsection{Economics of assembling: The central trade-offs}

Our analysis of the dynamics of assembling is based on the idea that assembling processes are centred around a (or a set of) core module(s). The assembling platform is progressively built by assembling around an initial service provision by a functionality producer who has incentives to combine new functionalities around its service. Microsoft, Google and many others were initially producers of individual and simple digital goods. They became assemblers by adding many additional services to their original supply. Various potential assemblers have different incentives and capabilities when it comes to assembling packages around their initial service. This results in competition between packages with contrasted differentiation and pricing capabilities due to the nature of the core modules. We believe the competition among packages is influenced by two sets of factors: the assembling strategy and the valorisation scheme.

The assembling strategy refers to the scope of the targeted assembling and to the depth of targeted integration between functionalities. Even if digital technologies rely on quite universal standards of interfaces, it is often necessary to make additional efforts to guarantee strong interoperability between functionalities. Thus, an assembler either chooses to rely on the universal standards, which allow him to assemble a wide number of modules, or on proprietary supplementary standards (or ad-hoc gateways), which enable him to provide a highly integrated package. In the case of the former, a wide diversity of services is available in the package but they remain relatively badly integrated. In the latter, since integration costs must be borne, fewer services are provided in the package but they are provided with "enhanced" quality due either to interoperability between them or to specific design. This latter case is well illustrated by the strategy used by mobile phone operators with the development of broadband mobile telephony, geo-localization capability and the constant enhancement of portable electronic equipment. They tend to bundle a limited number or services which are, however, highly interactive, adapted to the specificities of portable devices and targeted for uses associated to modern nomadism. On the other hand, an Internet Service Provider provides de facto access to a vast range of services, which are neither targeted to a specific category of users nor seamlessly organized. De facto, there is a quality dilemma between diversity and integration, which results in reliability, user friendliness, bundling pricing, customization, etc.

The valorisation strategy refers to the way value is extracted from the users of the package. Either the package is provided on a pay per provision basis or it is provided for free (with possibilities to mix the two strategies by providing some functions for free and others in exchange for a counterpart). Of course, free provision does not mean that there is no cost for the user. The platform needs to create value to cover its costs and those of the function providers. With reference to the media model, where advertising revenue funds the provision of information and entertainment since the users' attention is of value to the advertisers (for example, Anderson and Gabszewicz, 2006), the assembling platform values access and use. With digital technologies, two essential valorisations are possible. First, as in the media model, user attention can be sold to advertisers. Second, information can be extracted from users - either by requesting they provide information or by tracking their behaviour - to generate databases that are of value for different marketing practices: studying satisfaction levels, establishing scoring, profiling to target the communication of 
commercial offers, creating packages, etc. ${ }^{9}$ In both cases, there is a cost paid by the user. In the former, his service is "polluted" by unwanted content. In the latter, his privacy is questioned and he may suffer from intrusive marketing methods. There is, therefore, another quality dilemma, which contrast packages characterized by "pollution" costs and packages in which "pollution" is limited. It is worth noting that this notion of "pollution" can be extended to unfiltered and over abundant content and modules that lead the user to dedicate resources for testing, sorting and selecting. The ability to choose one of either valorisation strategies strongly depends on the costs of exclusion. When it is costly to exclude users from access to a function (at least compared to the revenues that could be expected from selling it), the free provision in exchange for pollution is likely to be preferred by the platform. This strategy aims at maximizing (even a targeted) audience and enriching its database as much as possible. When it remains profitable to exclude users from access, the platform can either provide for free and generate derived revenues, or rely on its sales to cover costs. The marketing choice for a platform is therefore between the free provision of "polluted" packages and the priced provision of value-added packages; this latter characteristic being reinforced by the fact that paying customers are likely to expect added value in exchange for a fee/subscription-based access to a service.

To illustrate, our framework helps understand current strategies and the evolution of competition in the Internet industries. This evolution can be explained as follows. Until mid- 2000, there was a clear separation between the access provision and content markets. Competition between models existed in each of them, the first one between ISPs and telecom operators, the second between various information service providers.

- The market for access is characterized by excludability since, by definition, an access provider controls the gateway to accessing network services. ISPs and Telcos were progressively led to provide access on a fixed subscription fee basis because of the fixed cost nature of the service. In a second step, competition between access providers led them to assemble several services to progressively provide seamless access to digital networks. This is the convergence taking place today toward "multiple-play" access in terms of fixed access (that is, Internet, TV and telephone), and seamless access between mobile and fixed access. Differentiation and quality strategies also have led access providers to assemble contents. Of course, free content is accessible on the Internet but providing exclusive access to additional or specifically designed content is an added value.

- On the content market, the "media model" has progressively become the dominant one since it is costly to exclude users from access to information ${ }^{10}$.

\footnotetext{
${ }^{9}$ At first sight, one could consider a third case in which free access is a loyalty tool for selling additional goods on a regular basis, either because users have an extremely high propensity to pay for some specific services that complement the package or because there is a two-sided market where some participants are ready to pay a high price to access the users of the platform. However, it is not relevant to do so. The former case corresponds to a hybridization strategy which can be implemented because some modules are easily excludable and can be sold on a standard commercial basis, the non-excludable modules being simply provided to create loyalty and differentiation. The latter case corresponds to a two-sided market problem in which the assembler is simply a matching platform.

${ }^{10}$ Obviously, many technologies exist to prevent access but they are costly to implement. This is reinforced by the fact that many categories of users do not consider it legitimate to pay for many types of information goods and so develop strategies to by-pass electronic barriers. Moreover, online payments can be expensive to manage and are most of the time quite inefficient for micro-payments. These have led many fee-based
} 
Today, on the Internet, most of the content is provided for free in exchange for several types of "pollution". Competition for audiences progressively led the various models to assemble an increasing number of services, as illustrated by Yahoo! or Google. The various "functions" are only poorly integrated among each other and are generally not provided on an exclusive basis since the goal is to enlarge the audience at the lowest possible cost (because there is no access fee). Progressively, the dominant players have been led not only to aggregate information services, but also access services. This is well illustrated by the provision of free Wi-Fi access by Google in California and by the take over of Skype by Yahoo.

One can therefore expect increasing frontal competition between the two types of models, since the dominant players on each market have incentives to expand by penetrating the other's market: "access" assemblers tend to assemble content; "media" assemblers tend to add access services to their contents. In the present stage of evolution, it is clear that this competition is still emerging and that the two types of assemblers are clearly developing different models targeting different market segments. "Access" assemblers are "naturally" led to target "value added" markets where the consumers, usually professionals, have a high propensity to pay for seamless ubiquitous and broadband access to specialized content. "Media" assemblers have incentives to assemble as much free information and digital services as possible. They are unable, however, to strongly integrate them. In a distant future, however, these models could converge. Both types of player could develop mixed assembling strategies, combining value-added packages generating direct revenues and standard quality packages valued on the basis of indirect revenues.

\section{The economics of knowledge management}

In the following, we explore the main phenomena highlighted by literature on the digital management of knowledge and innovation. It focuses, first, on the systematic accumulation of knowledge enabled by IT (section 5.1). Then, the various relevant dimensions of the economics of information and knowledge sharing are highlighted through discussion and analysis of the nature of knowledge as a commodity for understanding the conditions for sustainability of information sharing processes (5.2.). This gives rise to two different strands of analysis. The first focuses on the efficient organization of information exchanges (5.2.1); the second on the incentives for sharing and contributing (5.2.2).

\subsection{Knowledge management and public goods}

One of the key characteristics of digital business models is the will to systematically manage the information and knowledge that can be produced and extracted from the users of the digital goods and services. This corresponds to a deepening of fundamental trends that have been characterizing the growth in our consumer society and knowledge-based economy, characterized by the increasing sophistication of marketing methods to extract information from consumers to better adapt the supply to their preferences (and also to

information services to fail and explain why the dominant model is the one based on free access to content linked to derived revenues. See, for example, Curien and Moreau (2007). 
shape the latter), and to the recognition of the central role of users' feedbacks in innovative processes. This trend has been reaching a kind of achievement with the development of innovation process almost entirely based on users' contributions, as illustrated by the case of open source software (OSS). The OSS, however, is far from being the sole "business model” relying on users' contributions and feedbacks. Plenty of literature exists on how the ubiquity, seamlessness, and integration of digital technologies favour knowledge management processes that result in innovation.

Beyond the falling costs for gathering, sorting, storing and retrieving information, digital technologies empower the producers and users of information goods by providing them with capabilities to implement on a highly customized basis (if needed), specific rules for using and sharing information (Brousseau, 2003, 2007; and Elkin-Koren and Salzberger, 2004). These result in de-facto self-enforcing contracts or self-enforcing regulations, which allow for playing on incentives to produce information and to seek for efficiency in managing access and distribution. These capabilities are all the more central since digital technologies also leverage the ability to accumulate knowledge and make it usable for users. Tracking and storing capabilities, combined with seamless networks, and a universal language of codification generate an immense and pervasive repository of knowledge "embodied" in software, which are tools for codifying, accumulating, and distributing turnkey routines. This results in a cumulative process since, as pointed out by Bogenrieder and Nooteboom (2003) or D’Adderio (2003), for instance, the embedded knowledge and routines in software facilitate the further sharing of routines and knowledge among heterogeneous organizational groups.

The capacities of digital networks and technologies in terms of knowledge management do not apply only to what generally springs to mind when it is question of knowledge - that is, the conceptual, controlled and codified knowledge that characterize science - but also concern all types of information generated by day-to-day individual and collective activities. The Internet and related collective practices provide new ways of exchanging and sharing all kinds of information, including information on the quality of products, on past behaviour of potential traders, on tastes, preferences or opinions. If we refer to our analytical frameworks of digital business models, one can point out that digital networks allow for the accumulation of knowledge and information on its three dimensions: the matching one, since systematic tracking and the combination of information on transactions reduces transactional hazards, or allows more efficient matching between supply and demand; the assembling benefits from users' feedbacks, which enable the set of modules assembled to be adapted, or to enhance the quality of modules per se; cognition in itself benefits from tools enabling (more) efficient collective management of cooperation and knowledge (Table 1).

The structures of the problems are very similar in all the processes of knowledge generation described in Table 1. There are various alternatives for organizing information flows, access to information, incentives to disclose information and to contribute to common goods. Indeed, discussions on the problems of organization of OSS (for example, Bessen, 2004, Bonaccorsi and Rossi, 2002, 2003; and Camp, 2001) refer to problems that are the same as those of concern when dealing with the provision of trust among online traders (for example, Baron, 2002; Bakos and Dellarocas, 2003; and Dellarocas, 2003, 2004). 


\begin{tabular}{|c|c|c|c|}
\hline \multirow{3}{*}{ Transaction } & Trust & Tracking and reputation management & \multirow{3}{*}{$\begin{array}{l}\text { E-Bay } \\
\text { Amazon } \\
\text { C. Of Experience } \\
\text { FAQs } \\
\text { Epistemic C. of } \\
\text { Users }\end{array}$} \\
\hline & Matching & $\begin{array}{l}\text { Sharing of knowledge about } \\
\text { capabilities and needs }\end{array}$ & \\
\hline & Risk reduction & $\begin{array}{l}\text { Facilitating use by sharing learning by } \\
\text { using }\end{array}$ & \\
\hline \multirow{2}{*}{ Assembling } & $\begin{array}{l}\text { Products (components) } \\
\text { enhancement }\end{array}$ & $\begin{array}{l}\text { Gathering of information about } \\
\text { satisfaction \& solution }\end{array}$ & $\begin{array}{l}\text { Hot-Lines \& } \\
\text { Forum }\end{array}$ \\
\hline & Package enhancement & $\begin{array}{l}\text { Gathering of information about } \\
\text { consumption decision and actual use }\end{array}$ & $\begin{array}{l}\text { Fidelization \& } \\
\text { Tracking }\end{array}$ \\
\hline \multirow[t]{2}{*}{ Cognition } & $\begin{array}{l}\text { Collective accumulation and } \\
\text { distribution of knowledge }\end{array}$ & $\begin{array}{l}\text { Sharing of existing stock of } \\
\text { knowledge and information goods }\end{array}$ & $\begin{array}{l}\text { P2P } \\
\text { Open Archives } \\
\text { Epistemic C }\end{array}$ \\
\hline & Innovation & $\begin{array}{l}\text { Collective management of innovation } \\
\text { processes }\end{array}$ & OSS \\
\hline
\end{tabular}

Table 1: Digital networks as tools for accumulating and generating heterogeneous types of knowledge

\subsection{Conditions for sustainable and efficient knowledge sharing processes}

\subsubsection{The organization of information exchanges}

The bulk of literature on digital knowledge/information sharing focuses either on analyzing incentives for contributing or on the consequences of sharing platforms on the organization of the market and industries (for example, competition with traditional information goods providers, changes in the distribution of information and information asymmetries, etc.). Fewer contributions have insisted on the organizational conditions guaranteeing the efficiency of information exchanges.

Curien et al, (2007) show, however, that incentives to contribute, and therefore the self-sustainability of online communities (in their case, dedicated to the management of knowledge about products: information on quality, after-sale services, etc.), vary given the type of communities and the type of information exchanged. This leads them to point out that certain types of communities can be organized by intermediaries, while others should be organized by the providers of the products (functionalities in our model), both because of incentives and quality of information, which can be public goods (comparative information on products) or club goods (information on how to use products). On a totally different topic - the organization of OSS communities - Kogut and Metiu (2001) point out the importance of the organization of exchanges within online communities. They state that the main fragility of OSS communities is that projects can "fork" into competing versions. Governance structures are built to manage conflict, reach consensus and constitutionally minimize this danger. Then authors like von Hippel show how the characteristics of the coordinators of OSS projects influence the output. For instance, when "lead users" are involved in a project, the outcome tends to be more "commercially attractive” (Franke and von Hippel, 2003).

We suggest three key aspects of the organization of information exchanges should be highlighted.

The first is the role of the coordinator. As pointed out by Gensollen (2007), most online communities are not networks of interpersonal relationships that spontaneously emerge from online meetings or from on-line proximities. They are built and organized by a coordinator, who creates or animates a common information corpus. Of course, this 
coordinator can be a group of individuals, an organization, or a single individual. In any case, what matters is its legitimacy because users need to trust its ability to organize information exchanges, especially by guaranteeing their quality and, if need be, their privacy $^{11}$. They therefore value its neutrality, as well as its real ability to consistently control access to the shared information common (which is highlighted, in particular, by O’Mahony (2003), and O'Mahony and Ferraro (2004)). This does not mean that users value in any case closed communities. Depending on the circumstances, they value the capability of the coordinator either to circumvent information exchanges, or to guarantee the capability to access and contribute. Given this ability to be neutral and control contribution, the coordinator is the guarantor of the quality of the shared knowledge and information; the best way of providing this service depends on the nature of the knowledge shared, the identity of the contributors/users, their inclusion in social networks and off-line institutional frameworks, etc. (Dahlander and McKelvey, 2005).

The second aspect mentioned by the literature is the organization of the circulation of information and contribution to the shared corpus of knowledge. To put it briefly, two extrema are often contrasted; full openness (everybody can contribute to anything on an equal basis) versus closeness (members of the "community" are granted different types of rights for contributing and assessing the contribution of others). Of course, openness favours rich and dynamic exchanges of information. It is, however, costly to use because it is abundant, un-hierarchized and subject to quality hazards. On the other hand, closed and controlled contributions control the quality and usability of the output but bear, of course three main costs. First, fewer options are explored, which may hinder innovation and its quality. Second, there are organizational costs since resources are spent on controlling contributors and users of common goods. Third, there are agency costs since the preferences of the coordinator(s) may be different from these of the contributors/users, which may result in capture of the generated knowledge or in discrepancies between the expectations of contributors and the problems actually addressed by the collective knowledge. Debate on these issues often highlights the hybrid nature of peer communities (scientific and OSS communities, in particular), which mix closeness - hierarchical quality control in journal boards and kernels of developers - with openness; that is the freedom provided by the status of academics in science and the capability of "forking" in software. Again, there are trade-offs among the various options and the best one depends on the circumstances and preferences of the communities in question.

The third aspect highlighted by the literature is the management of the division of labour among contributors. Two sets of issues are highlighted. First, is there a division of labour or not? Second, if yes, on what criteria it is based? The first issue addresses the question of the redundancy of contributions and their relative quality. The ex-ante division of tasks avoids duplicating efforts and reduces the costs of assembling the generated knowledge (that is, the cost of sorting contributions and adapting them to each other expost). It obviously involves opportunity costs since opportunities of innovation are lost, and since the quality of innovation can be hindered by agency problems. Efficiency gains and costs of dividing labour however strongly depend on the criteria used to design and

\footnotetext{
${ }^{11}$ The notion of privacy on digital networks is quite complex since, on the one hand, many users enjoy sharing intimate information with other peers (which stay however distant because the only proximity with them is in the "virtual" world or because identities are faked), while on the other hand, most users do not want to let their neighbours or the organizations that directly impact their life (the state, their employers, their suppliers, etc.) match their online exchanges with their identity and behavior in the "real” world.
} 
allocate tasks. As pointed out by von Krogh et al (2003), for instance, in OSS communities, tasks are divided and allocated to favour specialization and innovation while in commercial firms, the goal is to control information flows and leakage. This leads to a differing balance in incentives to contribute, the quality of contributions and consistency (and therefore cost of use) of the collective innovation/repository of knowledge produced thanks to alternative organizational arrangements.

To sum up, literature on digital sharing of knowledge and information highlights the key role of coordinators, whose gatekeeper capabilities enable them to regulate "communities" of contributors to collective repositories of knowledge that form the heart of groups that mimic epistemic communities without being based on inter-personal relationships. Those regulators can manipulate various IT capabilities to organize contributions and the circulation of information. These tools generate de-facto organizations since they lead to the creation of elites and hierarchies. Alternative organizational designs manage the quality of individual contributions (including incentives to contribute), the dynamic of the collective accumulation of knowledge, and adequacy between means of innovation (competencies) and goals.

\subsubsection{Managing incentives to contribute}

Circa the beginning of 2000, academic studies on individual motivation for participating in open innovation process projects gave rise to heated controversy between two parties those who analyzed the open innovation movement as being built on intrinsic individual motivation to generate public goods and those who saw it as a movement based on selfish interest. This is an important issue for digital business models since, as pointed out by Frey and Oberholzer-Gee (1997), Fehr and Gächter (2002), and Benabou and Tirole (2003, 2007), a "crowding out" effect can arise if incentive schemes aimed at stimulating contribution are applied while intrinsic motivation (altruism, fairness, etc.) are at play and drive voluntary contributions.

On the one hand, Lerner and Tirole (2002) point out that many programmers involved in OSS development were receiving strong extrinsic benefits in the form of direct and immediate rewards (quality and customized program benefits, associated sales of services such as assembling services for lay users, compensation paid by employers interested in developing open and free software, etc.). They also emphasise the existence of delayed payoffs from open source projects - the career concern incentive, which relates to future job offers or future access to the venture capital market - and the ego gratification incentive, which stems from a desire for peer recognition. These two types of incentives group together as the signalling incentive, since Lerner and Tirole think the desire for social recognition can be interpreted in terms "career concerns" (Holmström, 1999). On the other hand, Lakhani and Wolf (2003) find that enjoyment-based intrinsic motivation, namely how creative a person feels when working on a project, is the strongest and most pervasive driver of contributions in OSS communities. They also find that user needs, intellectual stimulation derived from writing code and improving programming skills are top motivators for project participation. Haruvy et al (2003) show that programmers are less motivated if they observe commercial marketing of the open source software they helped create, leading to a reduction in improvements to the software. Intrinsic motivation is confirmed in the survey by Hertel et al (2003)

To sum up how literature focusing on online information and knowledge sharing analyzes incentives to contributing to the building of common information repositories, we 
examine, in turn, issues of individual motivation, institutional frameworks and coordinators.

Agents are potentially interested in a wide set of returns on their investment, even in the absence of market mechanisms. Of course, where such a system exists, they can benefit from monetary remuneration. However, in many cases, the higher quality of service they receive in exchange for their contribution suffices. Swapping information goods has many advantages due to the fact that many of these goods have a low individual value that is difficult to evaluate. Unlike for tangible goods, barter tends to save transaction costs in the information economy. The third type of expected return from contributions is the signalling effects that result from the recognition of authorship. Social recognition is a reward per se and may also result in fringe benefits (career concerns). The fourth type of expected return is strategic effects. This is well illustrated by the viral effects looked for in copyleft models of distribution. In a world where there is competition between technologies and standards, between ideas and values, it may prove worthwhile for a contributor to release their information and knowledge for free and even to subsidize its adoption and absorption, especially since fringe benefits can be expected from this distribution. These four motivations to contribute clearly do not systematically call for the implementation of market exchange. However, they have to be sustained by some mechanisms for controlling access and use of information. Indeed, barter, recognition of authorship, or adoption of common practices could not occur if information goods could be accessed, used and transformed without compliance to some rules. The contributors themselves can implement these rules within information goods in general (thanks to code and restricted access to common information spaces) but they can also be established by a (public or private) regulator that would set an adequate institutional framework. The advantage of the latter collective solution, compared to the former individual one, is that it can be less costly and more efficient since the collective regulator can take into account interdependence between agents and the specific characteristic of public goods (see Brousseau and Raynaud, 2007, on the benefits and costs of centralizing governance).

Designing an adequate (collective) institutional framework is therefore vital. The literature highlights the high cost of implementing a market mechanism when contributions are difficult to evaluate and of low (individual) value (for instance in P2P communities see Krishnan et al, 2007). Collective rules can, however, be implemented to manage the various "qualitative" returns (quality of service and reputation, in particular) expected by contributors. Digital technologies facilitate their implementation both because they make tracking of individual behaviour easier (automated tracking, peer rating, etc.) and because they provide tools for punishing infringement at a relatively low cost (stigmatization, ostracization). They also provide tools facilitating the recognition of authorship (for example, tagging but also digital rights management) and the management of symbolic remuneration (for example, various reputation proxies like Google or SSRN rankings). At the same time, while all these mechanisms are facilitated by the technology, their efficient performance depends on individual incentives and the embeddings of those who operate them in relational networks and institutional frameworks. While they work efficiently in small worlds made up of strong interpersonal links, they tend to suffer from tension when networks are loose, decentralized and not institutionally embedded. Indeed, technologies enable identities to be manipulated and the faking of exchanges. Furthermore, weak links between participants in the system result in a lower tendency to retaliate, and therefore, to enforce. 
In this context, coordination platforms play a central role. In the absence of a common institutional framework on a global scale and of strong links between agents potentially interested in building collective repositories of knowledge, for whom such repositories can be marginal stakes ${ }^{12}$, collective regulation will never emerge and be maintained. So for knowledge sharing, coordinators are therefore essential, and they build collective (private) regulations by designing rules governing the access to and use of information corpuses or exchange platforms (Gensollen, 2007). Their role is vital because they are responsible for maintaining incentive compatibility to guarantee participation and contribution in the long run. Since they are visible, they may have adequate incentives to provide efficient knowledge sharing and building services, which means, in particular, that they are restrained (by potential competition) from capturing a too large share of the information rent they benefit from by organizing the platform and being the owner (in some cases) of the databases built, thanks to individual contributions. In this respect, strong competition between knowledge sharing platforms is a good guarantor of their fairness and efficiency. As observed on many markets, especially on end user markets (for example, P2P music platforms), switching costs for users is quite low and potential competition is therefore strong, despite dominant players (for example Google, Yahoo!).

\subsection{Economics of knowledge management: The central trade-offs}

Our analysis of the key knowledge management choices faced by creators of digital business models is based on the idea that whenever the platform designer opts for a commercial model or a more cooperative one, he must choose both a principle for managing contributions and uses, and a regime to incite participants/users to/of the resulting cognitive platform.

The first dimension therefore involves organizing the information extraction process, circulation and use. Two extrema can be compared. On the one hand, tasks can be precisely assigned to the different participants that are even controlled in the way they use the extracted information. The process of knowledge creation is hierarchic and organized. It reduces quality hazards and provides secure access to the resulting innovation (by controlling leakages, in particular). It obviously comes at a cost, since information flows and the distribution of knowledge are difficult to control. Costs are, in fact, due to two reasons. First, it is costly to design an efficient system that actually optimises the use of available means. These are the costs of designing an organization à la Marschak and Radner (1972) and of running that organization (since there are unavoidable "noises" in collective information processing). Moreover, there are also opportunity costs, since an efficient organization can be ineffective in that it is well designed but wrongly addresses the issue. Second, there are agency costs inherent to any collective organization in which tasks and decisions are delegated to an agent by a principal (or a group of). On the other hand, tasks and contributions can be totally unorganized, meaning that all the participants in the system contribute on an equal basis. Spontaneous and decentralized adjustments among peers drive the process of knowledge sharing and collective innovation. One can expect, of course, high costs linked to search efforts and redundancy. Also, key elements may not be provided because no player has an interest in investing in their production. The

\footnotetext{
${ }^{12}$ Indeed, for a consumer, access to information on a category of goods and supplier is useful, while his consumption decisions regarding these goods form only a small part of the decision he has to make in his/her daily life. The same applies to an OSS developer. Writing code is an essential part of his/her life, but there are many other dimensions to his/her utility function (Dalle and Julien, 2003).
} 
benefit of such a system is that it is more open and so should allow a higher rate of innovation (in particular, in the digital world, due to existing standards of interfaces). The impact on the type of innovation is unclear. It certainly favours adaptative innovation as compared to the centralized and hierarchical model (for reasons well developed by Aoki (1988) when analysing the J-firm). But it may also have some positive impact on radical innovation. In a world of standardized interfaces, decentralization spreads risks and allows inventors to propose radically new modules. Radical innovations however may require components and the assembling process to be redesigned, which is easier in a hierarchically organized innovation process.

The second dimension characterizing business models in terms of knowledge management is the way rights of access and use are manipulated to incite participants to contribute and allow them to benefit from the common pool of knowledge. The available solutions can be analyzed along a continuum delimited by the well-known categories of the economics of science and knowledge: "intellectual property rights" vs. "open-science" regimes. It indeed contrasts those platforms (or digital good providers) that try to capture the rights to controlling information generated by the use of a digital sequence or by voluntary contributions by users/innovators, versus those who leave the residual rights to the users/contributors. As pointed out in our framework, the user of a function (or of an assembled service) generates, passively or actively, information that can be of value for suppliers in general. This information ranges from data on how a digital set is used, to creations and inventions drawn from the content transmitted to the user. As compared to what happens in the real world, this information is more easily accessible and manageable in the digital world since it is created, stored, transmitted and processed at a very low cost on the same infrastructure than the one where the initial goods and services are produced and used. For instance, log files and cookies track Internet users and result in low cost profiling. Possible digital tags buried in digital sequences can identify the creators of the various components of a digital work of authorship, which would be based on borrowed contents. Consequently, the control of information derived from the use of information goods is of critical importance in digital business models. One can point out, in addition, that this control is also of importance because of the very nature of information. Intellectual property rights systems traditionally address the issue of spillovers among inventions and creations, which could harm the initial creator's recognized exclusive rights. Quotations and other principles systems - whether they concern works of art or technological inventions - recognize the contribution of prior creations and inventions, and enable the organization of transfers among property rights holders. In the same spirit, patent holders can implement "grant back" provisions in their technology licensing agreements, to benefit from rights of use on the inventions created by their licensees (see Bessy and Brousseau, 1998). In the digital world, these attempts to control information created by the user (or its value) tend to be systematic for three reasons: (i) information and knowledge are factors at play in the creation of new information or knowledge, (ii) information leakage can ruin the market value or the initial information and knowledge; (iii) the technology allows for the control, at lower costs, of the information generated.

For a digital provider, capturing the value created by users has three costs. First, he should negotiate access to its information (probably in exchange for part of the potential surplus) with the latter, and/or he should dedicate resources to capturing this information or controlling the way the user creates and "invents around" the transmitted function or service. Second, it decreases the user's incentive to generate relevant and accurate 
information or to innovate. In addition, one can mention that the value of the information provided by one user is often highly dependent on the information provided by other users. These strong externalities among information sets generated by various users add an additional constraint to the trade-offs digital suppliers must face. Closed systems based on the principle of IPRs are therefore costly to implement. They generate transaction costs. On the other hand, they incite the provision of quality and facilitate exchanges of information that are of value. Transaction costs can however deter the provision of information of low individual value (while useful), generating a sub-optimal level of distribution of public goods (anti-commons tragedy, as highlighted by Heller and Eisenberg, 1998). By contrast; the choice of a fully open-access system might lead to a traditional tragedy of the commons. Knowledge is generated if, and only if, the platform subsidizes or forces revelation.

It should be pointed out that "open access communities", such as those frequently established in peer-sharing, open source software, communities of practices, online forums, (etc.) rely on choices of hybridisation along two axes. First, information exchanges are organized in these communities where tiers and hierarchy exist. Most of them are built around kernels of core contributors and (charismatic) leaders, which use various methods to discipline the participants and avoid information leakage when too soon. Second, licensing regimes and informal codes of conducts implement de-facto differentiated rights of access and of use that are recognized by the various categories of players - for example, core developers, regular developers, beta testers, lay users - to provide them with adequate incentives to participate in the system. We are certainly neither in the pure hierarchic, nor in a pure spontaneous system of innovation, just as we are neither in a system of closed IPRs, nor in the regime of open science (where everybody can use the available knowledge as he/she wants). Open source licences, for instance, impose many constraints on users.

\section{A framework for building a typology of digital business models}

To sum up, a digital business model is a combination of the three roles played by platforms. The platform can be a pure market intermediary (like a dating service or market place), a pure assembler (like a Telco or on-line media), a pure knowledge manager (like the Wikipedia community), or can choose to combine two (like eBay, Google, or Yahoo!) or three of these roles (like online travel agencies or Amazon). Then, for each of these roles, the platform must position itself along two axis, which result in differing trade-offs (as illustrated in Figure 3).

Whether the platform acts as an integrated intermediary providing a packaged intermediation between the supply of functions/modules and demand or whether there are only providers of unbundled (and standardized) intermediation services, is key differentiating factor between models. Integrated intermediaries (that is, assemblers of intermediation services) can cross-subsidize between services and market players so as to provide a better service. The drawback is obviously that they can capture rents.

Competition among intermediaries is a second key differentiating factor. On the one hand, competition between platforms decreases their capability to capture rents. On the other, a more dominant position allows them to provide a more efficient service. 

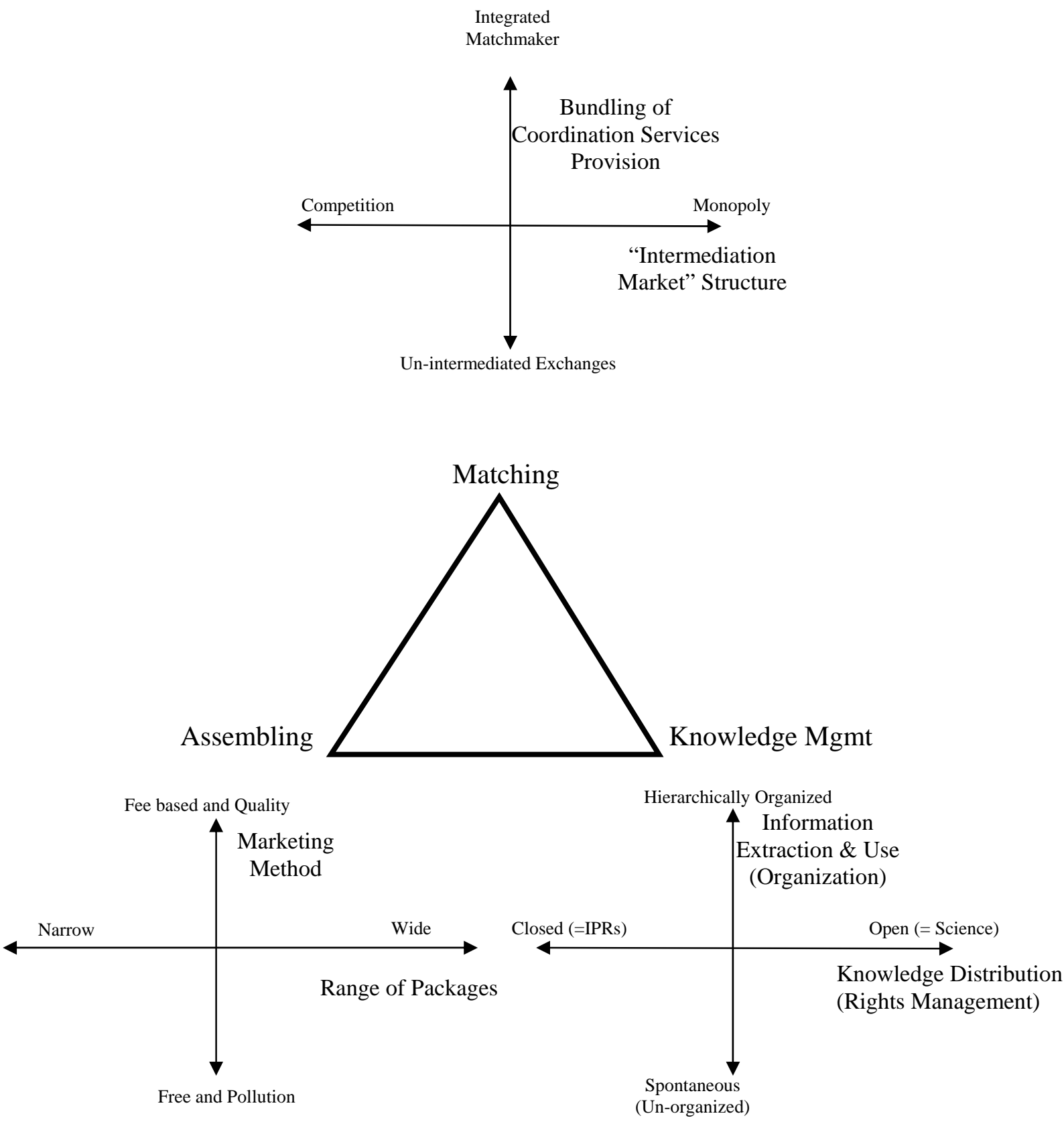

Figure 3: Trade-offs behind digital business models

Marketing methods create a dilemma for the assembler, between free services that tend to be polluted and packages sold on a fee-basis that correspond to demanded quality.

Assemblers have also to decide whether they assemble a wide set of modules in their packages or only a few. Narrower packages efficiently meet a category of needs, allow indepth integration and interoperability, enhance the ability of function providers to valorise their supply (through lower competition among them) and reduce assembling costs. However, the universal interface standards, which are characteristic of the digital world, provide incentives (which increase with the degree of competition among assemblers) to enlarge the range of assembled packages. This results in lower quality integration (since 
standards of interfaces are not perfect), in a reduced capability to differentiate and therefore to remunerate the provision of assembling and functions. Diversity is, however, a plus.

Platforms can also decide to organize the exchange of information; in which case they must bear organization costs and face the risk of making errors when managing the innovation/knowledge genesis process. Or they can decide to let information sharing organize itself, which results in a lower probability of achieving a consistent and complete innovation/repository of knowledge, in higher duplication costs (and even in conflicting efforts).

When the platform tries to implement a system allowing contributors to secure and exchange the information they generate, this results in a final trade-off. Individualized exclusive rights on pieces of information or knowledge increase the incentive to contribute and push for higher quality contributions. The costs are a lower level of distribution and high transaction costs that may hinder use of the available stock of information and knowledge. Open access result in the opposite effect.

These six dimensions describe the essential trade-offs behind digital business models. There is no optimal model but models that result in the best practical compromise between the specific nature of the assembled goods, the disparity and nature of users' preferences, production constraints faced by the function provider (level of costs, share of fixed costs in total costs, etc.), and the structure of competition between platforms.

We hope this framework delivers fresh and useful insights into digital business models. First, the presence of one or several platforms(s) does not prevent the existence of direct relationships between module producers and end users. Thus, alternative channels of distribution/aggregation may co-exist in a digital market. Second, the existence of dominant platforms may be better than several competing assemblers/intermediaries, since a monopoly platform is better able to provide its service to both market/industry sides. At the same time, dominant platforms tend to be challenged by new entrants that balance their lower efficiency by lower rent capture. This leads to a competition between different assembler models (who differentiate by adopting different approaches to function collection and aggregation modes). Third, platforms must be fair and neutral if they want to extract information and knowledge from users. They generally have to share the rent they could, in theory, capture, by organizing information exchange. Since potential competition always exists among platforms, the users and function producer (whose roles can partly overlap) of platforms are restrained from behaving too opportunistically and have strong incentives to provide the various parties with returns on their contributions to the platform (beginning by being a single user).

The complex combination of trade-offs highlighted in this paper deserves, however, more systematic and in-depth investigation. As proven by the papers mentioned here and the paper published in this special issue, some of these trade-offs have already been explored. However, this article aims to open up avenues of research, rather than attempting to draw conclusions. Further studies on the suitability of alternative models in different contexts and of the dynamics of competition between alternative models are needed. Our future research will focus on providing a better understanding of the rules of competition and valorisation in a world of generalized mass-customization and aggregation of goods that are increasingly intensive in information and knowledge, as do the other contributions in this special issue. 


\section{$7 \quad$ References}

Akerlof, G. A. (1970) “The Market for Lemons: Quality, Uncertainty and the Market Mechanism,” Quarterly Journal of Economics, 84: 488-500.

Anderson, S. and J.J. Gabszewitch (2006) "The Media and Advertising: aTale of two-sided Markets," in V.A. Ginsburgh and D. Throsby (ed.) Handbook of the Economics of Art and Culture, Elsevier: North Holland.

Aoki, M. (1988) Information, Incentives and Bargaining in the Japanese Economy. Cambridge University Press: Cambridge.

Arnold, M. and T. Penard (2007) "Bargaining and Fixed Price Offers: How Online Intermediaries are Changing New Car Transactions," Review of Network Economics, 6: 134-160.

Arrow K.J. (1962) "Economic Welfare and the Allocation of Resources for Invention," in R. Nelson (ed.), The Rate and Direction of Inventive Activity: Economic and Social Factors, Princeton University Press: Princeton.

Arrow, K. J. (1971) Essays in the Theory of Risk. North Holland Publishing: Amsterdam.

Aumann, R. and R. B. Myerson (1988) "Endogenous Formation of Links between Players and Coalitions: An Application of the Shapley Value,” in A. Roth (ed.), The Shapley Value, Cambridge University Press: New York.

Bakos, Y. (2001) “The Emerging Landscape for Retail E-Commerce," Journal of Economic Perspectives, 15: 69-80.

Bakos, Y. and C. Dellarocas (2003) "Cooperation Without Enforcement? A Comparative Analysis of Litigation and Online Reputation as Quality Assurance Mechanisms," Working Paper, New York University.

Bakos, Y. and E. Brynjolfsson (2000) "Bundling and Competition on the Internet," Marketing Sciences, 19: 63-82.

Bala, V. and S. Goyal (2000) “A Noncooperative Model of Network Formation," Econometrica, 68: 1181-1229.

Baron, D.P. (2002) "Private Ordering on the Internet: The eBay Community of Traders," Business \& Politics, 4: 245-274.

Baye, M.R. and J. Morgan (2001) "Information Gatekeepers on the Internet and the Competitiveness of Homogeneous Product Markets," American Economic Review, 91: 454-474.

Baye, M.R. and J. Morgan (2002) "Information Gatekeepers and Price Discrimination on the Internet,” Economics Letters, 76: 47-51. 
Benabou, R. and J. Tirole (2003) "Intrinsic and Extrinsic Motivation," Review of Economic Studies, 70: 489-520.

Benabou, R. and J. Tirole (2007) "Incentives and Prosocial Behavior," Forthcoming, American Economic Review.

Bessen, J.E. (2004) “Open Source Software: Free Provision of Complex Public Goods,” Working Paper, Research on Innovation.

Bessy, C. and E. Brousseau (1998) "Technology Licensing Contract: Features and Diversity,” International Review of Law and Economics, 18: 451-489.

Bogenrieder, I. and B. Nooteboom (2003) “Social Structures for Learning,” Erasmus University Rotterdam - Erasmus Research Institute of Management (ERIM) and Erasmus University Rotterdam - Faculteit der Bedrijfskunde (FBK).

Bonaccorsi, A. and C. Rossi (2003) "Why Open Source Software Can Succeed," Research Policy, 32: 1243-1258.

Bourreau, M., P. Dogan and M. Manant (2007) "Modularity and Product Innovation in Digital Markets,” Review of Network Economics, 6: 175.193.

Brousseau, E. (2002) “The Governance of Transaction by Commercial Intermediaries: An Analysis of the Re-engineering of Intermediation by Electronic Commerce," International Journal of the Economics of Business, 9: 353-374.

Brousseau, E. (2003) “Property Rights in the Digital Space,” in E. Colombatto (ed.), The Elgar Companion to the Economics of Property Rights, Edward Elgar: United Kingdom.

Brousseau, E. (2007) "Public and Private Governance of the Digital Space: Does a Second Rank Institutional Framework Exist?” in Brousseau E. and Curien N., (ed.), Internet Economics, Digital Economics, Cambridge: Cambridge University Press.

Brousseau, E. and E. Raynaud (2007) "The Economics of Multilevel Governance," Working Paper, University of Paris X.

Brousseau, E. and J.M. Glachant (2002) The Economics of Contracts: Theory and Application, Cambridge University Press: Cambridge.

Brousseau, E. and T. Pénard (2006) “The Economics of Assembling,” Working Paper, University of Paris X and Rennes 1.

Caillaud, B. and B. Jullien (2001) “Competing Cybermediaries,” European Economic Review, 45: 797-808.

Caillaud, B. and B. Jullien (2003) "Chicken \& Egg: Competition among Intermediation Service Provider,” RAND Journal of Economics, 34:309-328. 
Camp, J. (2001) “Sustainable Open Source Software Business Models,” in L. McKnight, P.M. Vaaler and R. L. Katz (eds.) Creative Destruction, MIT Press: Cambridge and London.

Curien, N. and F. Moreau (2007) "The Convergence between Content and Access: Internalizing the Market Complementarity” Review of Network Economics, 6: 161-174

Curien, N., E. Fauchart, G. Laffond and F. Moreau (2007) "Online Consumers Communities,” in E. Brousseau and N. Curien (eds.), Internet and Digital Economics, Cambridge University Press: Cambridge.

D'Adderio, L. (2003) “Configuring Software, Reconfiguring Memories: The Influence of Integrated Systems on the Reproduction of Knowledge and Routines," Industrial and Corporate Change, 12: 321-350.

Dahlander, L. and M. McKelvey (2005) "Who is not Developing Open Source Software? Non-users, Users, and Developers,” Economics of Innovation and New Technology, 14: 617-635.

Dalle, J.-M. and N. Jullien (2003) "Libre Software: Turning Fads into Institutions?" Research Policy, 32, 1-11.

Dellarocas, C. (2003) "The Digitization of Word-of-Mouth: Promise and Challenges of Online Feedback Mechanisms,” Management Science, 49: 1407-1424.

Dellarocas, C. (2004) "Building Trust On-Line: The Design of Reliable Reputation Reporting: Mechanisms for Online Trading Communities," in G. Doukidis, N. Mylonopoulos and N. Pouloudi (eds.), Information Society or Information Economy? A Combined Perspective on the Digital Era, Idea Group Publishing: Hershley.

Donsimoni, M.P. (1985) “Stable Heterogeneous Cartels," International Journal of Industrial Organization, 3: 451-467.

Donsimoni, M.-P., N. Economides and H. M. Polemarchakis (1986) "Stable Cartels," International Economic Review, 27: 317-327.

Dutta, B. and M. Jackson (2000) "The Stability and Efficiency of Directed Communication Networks,” Review of Economic Design, 5: 251-272.

Economides N. and E. Katsamakas (2006) "Two-Sided Competition of Proprietary vs. Open Source Technology Platforms and the Implications for the Software Industry," Management Science, 52: 1057-1071.

Economides, N. (1996) “The Economics of Networks,” International Journal of Industrial Organization, 14: 673-699.

Economides, N. and S. Salop (1992) "Competition and Integration Among Complements, and Network Market Structure,” Journal of Industrial Economics, 40: 105-112. 
Elkin-Koren, N. and E. Salzberger (2004) Law, Economics and Cyberspace. Edward Elgar: United Kingdom.

Fehr, E. and S. Gächter (2002) "Do Incentive Contracts Undermine Voluntary Cooperation?” Working Paper Series, Institute for Empirical Research in Economics, University of Zurich.

Franke, N. and E. von Hippel (2003) "Finding Commercially Attractive User Innovations: A Performance Evaluation of the Lead User Construct," Working Paper, Vienna University of Economics and Business Administration - General and Massachusetts Institute of Technology (MIT) - Sloan School of Management.

Frey, B. and F. Oberholzer-Gee (1997) "The Cost of Price Incentives: An Empirical Analysis of Motivation Crowding-Out,” American Economic Review, 87: 746-755.

Fulkerson, B. and M. Shank (2000) "The New Economy Electronic Commerce, and the Rise of Mass Customization,” in M. Shaw et al (ed.), Handbook on Electronic Commerce, Springer: Berlin.

Gensollen, M. (2007), “Information Goods and Online Communities,” in Brousseau E. \& Curien N. (eds.), Internet and Digital Economics, Cambridge University Press: Cambridge.

Goyal, S. and S. Joshi, (2003) "Networks of Collaboration in Oligopoly," Games and Economic Behavior, 43: 57-85.

Hagiu (2007) “Merchant or Two-Sided Platform?” Review of Network Economics, 6: 115133

Hand, J.R.M. (2001) "Evidence on the Winner-takes-all Business Model: The Profitability Returns-to-scale of Expenditures on Intangibles Made by U.S. Internet Firms, 1995-2001,” Working Paper, University of North Carolina.

Haruvy, E., A. Prasad and S. Sethi (2003) "Harvesting Altruism in Open Source Software Development,” Journal of Optimization Theory and Applications, 118: 381-416.

Hawkins, R. (2002) "The Phantom of the Marketplace: Searching for New E-Commerce Business Models,” Communications and Strategies, 46: 297-329.

Heller, M. and R. Eisenberg (1998) “Can Patents Deter Innovation?” The Anticommons in Biomedical Research Science, 280: 698-701.

Henkel, J. and E. von Hippel (2005) “Welfare Implications of User Innovation,” The Journal of Technology Transfer, 30: 73-87.

Hertel, G., S. Niedner and S. Herrmann (2003) "Motivation of Software Developers in Open Source Projects: An Internet-Based Survey of Contributors to the Linux Kernel," Research Policy, 32: 1159-1177. 
Hirst, P. (1997) "Flexible Specialization: Theory and Evidence in the Analysis of Industrial Change," in J. Zeitlin (ed.), Contemporary Capitalism: The Embeddedness of Institutions. Cambridge Studies in Comparative Politics, Cambridge University Press: New York.

Holmstrom, B. (1999) “Managerial Incentive Problems - A Dynamic Perspective,” Review of Economic Studies, 66: 169-182.

Jackson, M. and A. Watts (2002) "The Evolution of Social and Economic Networks," Journal of Economic Theory, 106: 265-295.

Jackson, M. and A. Wolinsky (1996) "A Strategic Model of Economic and Social Networks,” Journal of Economic Theory, 71: 44-74.

Kogut, B and U. Zander (1996) "What Firms Do? Coordination, Identity, and Learning," Organization Science, 7: 502-518.

Kogut, B. and A. Metiu (2001) "Open-Source Software Development and Distributed Innovation,” Oxford Review of Economic Policy, 17: 248-264.

Krishnan, R., M.D. Smith, Z. Tang and R. Telang (2007) "Digital Business Models for Peer-to-Peer Networks: Analysis and Economic Issue,” Review of Network Economics, 6: 194-213.

Lakhani, K.and R.G. Wolf (2003) "Why Hackers Do What They Do: Understanding Motivation and Effort in Free/Open Source Software Projects," Working Paper, Massachusetts Institute of Technology (MIT) - Sloan School of Management and The Boston Consulting Group

Lancaster, K. (1979) Variety Equity and Efficiency. Basil Blackwell: Oxford.

Lee, C.-H.S., A. Barua and A. Whinston (2000) "The Complementarity of Mass Customization and Electronic Commerce," Economics of Innovation and New Technology, 9: 81-109.

Lerner, J. and J. Tirole (2002) “Some Simple Economics of Open Source,” Journal of Industrial Economics, 50: 197-234.

Lucking-Reiley, D. and D. Spulber (2001) "Business-to-Business Electronic Commerce," Journal of Economic Perspectives, 15: 55-68.

Marschak, J. and R. Radner (1972) Economic Theory of Teams. Cowles Foundation and Yale University Press: New Haven.

McKelvey, M. (2001) “The Economic Dynamics of Software: Three Competing Business Models Exemplified through Microsoft, Netscape and Linux, in Innovation in the Telecommunication Industry," Economics of Innovation and New Technology, 11: 127164. 
Melo de Brito Carvalho, T.C. and M. Siegel (2002) "Return on Investment from Online Banking Services: An Analysis of Financial Account Aggregation,” MIT Sloan Working Paper No. 4384-02, Massachusetts Institute of Technology (MIT) - Sloan School of Management.

Myerson, R. (1977) "Graphs and Cooperation in Games," Mathematics of Operations Research, 2: 225-229.

O'Mahony, S. (2003) "Guarding the Commons: How Community Managed Software Projects Protect Their Work,” Research Policy, 32: 1179-1198.

O'Mahony, S. and F. Ferraro (2004) "Managing the Boundary of an 'Open' Project," Working Paper, Harvard Business School.

Parker, J. G. and M.W. Van Alstyne (2000) "Information Complements, Substitutes, and Strategic Product Design,” Working Paper, Tulane University.

Piller, F. (2002) "Customer Interaction and Digitizability - A Structural Approach to Mass Customization,” in C. Rautenstrauch et al (ed.): Moving towards Mass Customization. Springer: Berlin.

Pisano, G.P. (1990) "The R\&D Boundaries of the Firm: An Empirical Analysis," Administrative Science Quarterly, 35: 153-176.

Rochet, J.-C. and J. Tirole (2002) "Cooperation among Competitors: Some Economics of Payment Card Associations,” RAND Journal of Economics, 33: 549-570.

Rochet, J.-C. and J. Tirole (2003) "Platform Competition in Two-Sided Markets,” Journal of the European Economic Association, 1: 990-1029.

Rochet, J.C. and J. Tirole (2007) “Two-Sided Markets: A Progress Report,” Rand Journal, forthcoming.

Shapiro, C. and H. Varian (1999) Information Rules: A Strategic Guide to the Network Economy. Harvard Business School Press: Cambridge.

Spulber, D.F. (1996) “Market Microstructure and Intermediation,” Journal of Economic Perspectives, 10:135-152.

Spulber, D.F. (1999) Market Microstructure: Intermediaries and the Theory of the Firm. Cambridge University Press: New York.

Spulber, D.F. (2003) “The Intermediation Theory of the Firm: Integrating Economic and Management Approaches to Strategy,” Managerial and Decision Economics, 24: 253-266.

Stiglitz, J. E. (1977) "Monopoly Nonlinear Pricing and Imperfect Information: The Insurance Market,” Review of Economic Studies, 44: 407-430. 
Teece D. J., R. Rumelt, G. Dosi and S. Winter (1994) "Understanding Corporate Coherence: Theory and Evidence,” Journal of Economic Behavior \& Organization, 23: 130.

Varian, H. (2000) "Market Structure in the Network Age”, in E. Brynjolfsson and B. Kahin (ed.), Understanding the Digital Economy, MIT Press: Cambridge.

von Krogh, G., S. Spaeth and K.R. Lakhani (2003) "Community, Joining, and Specialization in Open Source Software Innovation: A Case Study,” Research Policy, 32: 1217-1241.

Vrechopoulos, A.P. (2004) "Mass Customisation Challenges in Internet Retailing through Information Management,” International Journal of Information Management, 24: 59-71.

Williamson, O.E. (1975) Markets and Hierarchies: Analysis and Antitrust Implications. A Study in the Economics of Internal Organization. Free Press: New York.

Williamson, O.E. (1985) The Economic Institutions of Capitalism: Firms, Markets and Relational Contracting. Free Press: New York.

Wright, J. (2004) "One-sided Logic in Two-sided Markets," Review of Network Economics, 3: 44-64. 